\title{
Effect of the electrolyte cations on photoinduced charge transfer at $\mathrm{TiO}_{2}$
}

\author{
A. Molinari ${ }^{\mathrm{a}}$, A. Maldotti ${ }^{\mathrm{a}}$, R. Amadelli ${ }^{\mathrm{b}, *}$ \\ a Dipartimento di Scienze Chimiche e Farmaceutiche, Via Fossato di Mortara 17, 44121, Italy \\ b ISOF CNR, UoS di Ferrara, c/o Dipartimento di Scienze Chimiche e Farmaceutiche, Via Fossato di Mortara 17, 44121, Italy
}

\section{A R T I C L E I N F O}

\section{Article history:}

Received 23 February 2016

Received in revised form 11 August 2016

Accepted 9 September 2016

Available online $\mathrm{xxx}$

\section{Keywords:}

Photocatalysis

Alkaline metal ions

Titanium dioxide

Adsorption

Cations photoinsertion

EPR spin trapping

\begin{abstract}
A B S T R A C T
This work focuses on the effect of electrolyte cations on the behaviour of a probe photocatalytic system comprising 2-propanol and 4-nitrobenzaldehyde $\left(\mathrm{O}_{2} \mathrm{NC}_{6} \mathrm{H}_{4} \mathrm{CHO}\right)$ as the hole and electron scavenger, respectively. Photo-reduction of the latter occurs via a stepwise pathway involving 4-aminobenzaldehyde $\left(\mathrm{H}_{2} \mathrm{NC}_{6} \mathrm{H}_{4} \mathrm{CHO}\right)$ as the stable intermediate and 4-aminobenzyl alcohol $\left(\mathrm{H}_{2} \mathrm{NC}_{6} \mathrm{H}_{4} \mathrm{CH}_{2} \mathrm{OH}\right)$ as the final product. 2-propanol photo-oxidation produces protons at the surface.

The complete reduction of $\mathrm{O}_{2} \mathrm{NC}_{6} \mathrm{H}_{4} \mathrm{CHO}$ to $\mathrm{H}_{2} \mathrm{NC}_{6} \mathrm{H}_{4} \mathrm{CH}_{2} \mathrm{OH}$ needs photo-charging. Excess negative charge is compensated by cations adsorption and by lattice insertion. In the case of bulky $\mathrm{K}^{+}$and TEA (tetraethylammonium ions) that apparently are not inserted, protons are inserted instead. In contrast, $\mathrm{Li}^{+}$(and to a lesser degree $\mathrm{Na}^{+}$) ions favour selective reduction of $\mathrm{O}_{2} \mathrm{NC}_{6} \mathrm{H}_{4} \mathrm{CHO}$ to $\mathrm{H}_{2} \mathrm{NC}_{6} \mathrm{H}_{4} \mathrm{CHO}$.

Electrochemical measurements in the dark provide evidence of a strong interaction of 2-propanol with the surface and of the influence exerted by cations thereon. Additionally, electron paramagnetic resonance (EPR) spin trapping spectroscopy gives information about the formation of radicals intermediates from the alcohol photo-oxidation. Repeated illumination/dark runs showed that alkoxy (R-O*) radicals always formed when the electrolyte contains $\mathrm{K}^{+}$or $\mathrm{TEA}^{+}$. Conversely, in prolonged experiments, $\mathrm{Li}^{+}$favours the formation of hydroxyalkyl radicals $(\mathrm{R}-\mathrm{C} \bullet \mathrm{HOH})$, which indicates a non-dissociative interaction of 2-propanol with the surface. This weaker interaction can be reasonably ascribed to the know ability of $\mathrm{TiO}_{2}$ inserted $\mathrm{Li}^{+}$to cause the formation of a new phase of the type $\mathrm{Li}_{\mathrm{x}} \mathrm{TiO}_{2}$.
\end{abstract}

(c) 2016 Elsevier B.V. All rights reserved.

\section{Introduction}

Photocatalysis [1,2] and photoelectrocatalysis [3,4] for green and sustainable syntheses on $\mathrm{TiO}_{2}$ are ever growing, interesting research fields. Researchers in semiconductor photocatalysis have always been conscious of the importance of studies on the mechanism of processes [5]. Our recent work in this field [6,7] was motivated by interest in the role of surface energetics recognizing that the usefulness of photocatalysis depends critically on the energetic positions of the band edges relative to the solution species. Understanding and optimizing the semiconductor surface energetics may lead to significant improvements. In particular, electron accumulation represents a way of promoting control over band-edge positions (interface energetics). In this regard, dark elec-

\footnotetext{
* Corresponding author.

E-mail addresses: alessandra.molinari@unife.it (A. Molinari), rossano.amadelli@unife.it (R. Amadelli).
}

trochemistry in the accumulation regime (electrochemical doping) has been the subject of several publications [8].

It has been pointed out that reductive doping of $\mathrm{TiO}_{2}$ is also achieved upon illumination and is accordingly referred to as "photodoping" $[6,9,10]$. The reducing power of $\mathrm{TiO}_{2}$ can be changed by light, a phenomenon often termed light soaking in dye-sensitized cells studies. The cause is not clear but arguably identified as an increase of availability of states into which electrons can be transferred [11].

Important photocatalytic applications are found in the literature where control of selectivity in the formation of reduction products can be achieved by working in an electron accumulation regime [6,7,12]. Kohtani et al. [12] examined the photoreduction of acetophenone derivatives (APs) with different reduction potentials; they emphasised the mediating role of surface states in the photoreduction processes and estimated the amount of accumulated electrons using oxygen-free $\mathrm{TiO}_{2}$ suspensions that were pre-illuminated and subsequently added with the electron acceptors. The authors mention a discrepancy between band edge position and the reduction potential $\mathrm{E}^{\circ}$ red of the APs derivatives; 
the fact that APs are reduced is explained by a positive shift of $\mathrm{E}^{\circ}$ red due to interaction with the surface, which lowers the LUMO level of the species. The adsorption model is indeed convincing for the AP compounds that they examined.

In our earlier publication [6], we agreed with the validity of the adsorption controlled mechanism and the role of surface states in the reduction of the $-\mathrm{NO}_{2}$ functionality in $4-\mathrm{O}_{2} \mathrm{NC}_{6} \mathrm{H}_{4} \mathrm{CHO}$, used as the electron acceptor. The reduction of the $-\mathrm{CHO}$ functionality in this molecule required consideration of other factors in addition to adsorption. Following Cao et al. [13] we proposed that photoinduced accumulation of electrons in surface states would cause a potential drop at the solid/electrolyte interface, which leads to a shift of the bands [6]. Conduction band edge movements (unpinning) has been studied and discussed for a relatively long time [13] and an account is given in a recent, interesting paper by Mandal and Hamann [14]. In this connection, the influence of cations on semiconductor/electrolyte interfaces has been recognized for some time and has been the object of several earlier publications mainly aiming at the development of efficient dye-sensitized photo-electrochemical solar cells (DSSC) $[15,16]$ as well as $\mathrm{TiO}_{2}$ based electrochemical energy storage devices [17].

To our knowledge, our recent work [6,7] addresses for the first time the effect of electrolyte cations on both photocatalytic reduction and oxidation reactions occurring in a model photocatalytic system. The main aim of these studies is that of proving a tunable photocatalytic selectivity and, in this regard, we showed that the surface energetics and the reactions selectivity changes dramatically when $\mathrm{Li}^{+}$rather than tetraethylammonium $\left(\mathrm{TEA}^{+}\right)$is present in the medium. The intent of the present paper is to complement our previous work on the influence of electrolyte cations. Specifically, we complete our earlier investigations by comparing, in particular, the effects of $\mathrm{Na}^{+}$and $\mathrm{K}^{+}$with those of $\mathrm{TEA}^{+}$and $\mathrm{Li}^{+}$in order to provide a detailed picture of the influence of the nature of monovalent cations at the $\mathrm{TiO}_{2} /$ solution interface both in the dark and under illumination.

We use, as before [6,7], a probe photocatalytic system comprising 2-propanol and $4-\mathrm{O}_{2} \mathrm{NC}_{6} \mathrm{H}_{4} \mathrm{CHO}$ as the electron donor and acceptor, respectively. The complete transformation that takes place under illumination is

$$
\begin{aligned}
& \mathrm{O}_{2} \mathrm{NC}_{6} \mathrm{H}_{4} \mathrm{CHO}+4\left(\mathrm{CH}_{3}\right)_{2} \mathrm{CHOH} \rightarrow 4\left(\mathrm{CH}_{3}\right)_{2} \mathrm{CO} \\
& +\mathrm{H}_{2} \mathrm{NC}_{6} \mathrm{H}_{4} \mathrm{CH}_{2} \mathrm{OH}+2 \mathrm{H}_{2} \mathrm{O}
\end{aligned}
$$

We discuss conditions that lead to full reduction (reaction (1)) or to partial reduction forming a stable $\mathrm{H}_{2} \mathrm{NC}_{6} \mathrm{H}_{4} \mathrm{CHO}$ intermediate. From the point of view of mechanism analysis, it is also interesting to further examine the electrochemical and photocatalytic behaviour in the absence of an electron acceptor since in this case photo-charging occurs as a consequence of alcohol oxidation.

$\mathrm{TiO}_{2}\left(\mathrm{e}^{-} / \mathrm{h}^{+}\right)+\left(\mathrm{CH}_{3}\right)_{2} \mathrm{CHOH} \rightarrow \mathrm{TiO}_{2}\left(2 \mathrm{e}^{-}\right)+2 \mathrm{H}^{+}+\left(\mathrm{CH}_{3}\right)_{2} \mathrm{CO}$

As stated above, electron accumulation, denoted as $\mathrm{TiO}_{2}\left(2 \mathrm{e}^{-}\right)$ in reaction (2), is a necessary condition for the reduction of species such as the $4-\mathrm{H}_{2} \mathrm{NC}_{6} \mathrm{H}_{4} \mathrm{CHO}$ whose $\mathrm{E}^{\circ}$ red is more negative than flat band potential $\left(\mathrm{E}_{\mathrm{fb}}\right)[6]$. Protons released at the surface in reaction (2) are then consumed in the reduction of $\mathrm{O}_{2} \mathrm{NC}_{6} \mathrm{H}_{4} \mathrm{CHO}$ (reaction (1)). We remark, additionally, that results of investigations on the photo-(electro) oxidation of alcohols are used to identify catalytically active sites on metal oxide surfaces in single-crystalline and/or powder form [18]. In this context, we devote particular attention to adsorption of 2-propanol and underline its importance in connection with reactivity, surface dynamics and charge transfer $[18,19]$.
We also take in due consideration that small cations such as $\mathrm{Li}^{+}$and $\mathrm{H}^{+}$are easily inserted into $\mathrm{TiO}_{2}[20,21]$ when this is subjected to negative potentials or to illumination. Insertion, occurring simultaneously with the reduction of $\mathrm{Ti}^{4+}$ sites by electrons, is well known to bring about alteration of the properties of $\mathrm{TiO}_{2}$ that are not expected in the case of $\mathrm{K}^{+}$due to its larger ionic radius.

\section{Material and methods}

Commercial $\mathrm{TiO}_{2}$ (Evonik, formerly Degussa P25) was used as photocatalyst. Solvents and reagents were commercial from Sigma-Aldrich. Anhydrous acetonitrile $(<0.001 \%$ water) was used as received after controlling the absence of spurious water through cyclic voltammetry of redox couples such as $\mathrm{O}_{2} / \mathrm{O}_{2}{ }^{-}$or the multielectron redox of (TEA) ${ }_{3} \mathrm{PW}_{12} \mathrm{O}_{40}$ which are reversible in the absence of protons (see Supplementary material). 2-propanol was first refluxed for $1 \mathrm{~h}$ in the presence of $\mathrm{Mg}$ and a catalytic amount of $\mathrm{I}_{2}$ and then distilled. $\mathrm{O}_{2} \mathrm{NC}_{6} \mathrm{H}_{4} \mathrm{CHO}$ (Fluka) and $\mathrm{LiClO}_{4}, \mathrm{NaClO}_{4}, \mathrm{KPF}_{6}$ (Sigma) were employed as purchased. Before experiments, $\mathrm{TiO}_{2}$ was dried using standard methods at 373-423 K under vacuum [22].

Electrochemical experiments were performed with an EG\&G potentiostat using EG\&G software. Glassy carbon and Ag wire electrodes served as the counter and reference electrodes, respectively. The potential of the latter was $0.025 \mathrm{~V}$ versus SCE through comparison of cyclic voltammograms of ferrocene as an internal standard. All potentials are reported versus SCE. Titanium dioxide electrodes were prepared by spreading, on a titanium foil, a paste obtained mixing $\mathrm{TiO}_{2}$ (P-25, $3 \mathrm{~g}$ ), as described earlier [6,7].

Experiments with illumination were carried out using a medium pressure mercury lamp (Hanau model Q 400) equipped with filters. Light intensity was measured by a Newport Power Meter model 1918C, equipped with a model $818 \mathrm{P}$ detector. The lamp has an intense emission line at $365 \mathrm{~nm}$ which was isolated, using Edmund Optics bandpass filters; the incident flux was $2.75 \times 10^{16}$ photons $\mathrm{s}^{-1} \mathrm{~cm}^{-2}$, calculated from the measured radiant power density in $\mathrm{mW} \mathrm{cm}^{-2}$. In a typical photocatalytic experiment, $\mathrm{TiO}_{2} \mathrm{P} 25(10 \mathrm{mg})$ was suspended in a solution $\left(3 \mathrm{~mL}\right.$ ) of $\mathrm{CH}_{3} \mathrm{CN} / 2$-propanol mixture (4/1) containing $\mathrm{O}_{2} \mathrm{NC}_{6} \mathrm{H}_{4} \mathrm{CHO}\left(1 \times 10^{-4} \mathrm{~mol} \mathrm{~L}^{-1}\right)$. The suspension was deaerated with $\mathrm{N}_{2}$ flux and then irradiated. After the illumination period, the sample was centrifuged and $\mathrm{O}_{2} \mathrm{NC}_{6} \mathrm{H}_{4} \mathrm{CHO}$ conversion and formation of product were monitored by UV-vis spectroscopy (Jasco V630 spectrophotometer). In the case of acetone, the reactor was kept closed with a silicon stopper and the solution to be injected $(1 \mu \mathrm{L})$ was taken using the suitable syringe.

Gas-chromatographic experiments were carried out with an Agilent 6890 instrument, equipped with a FID detector and a capillary column (DB-WAX, length $30 \mathrm{~m}$, internal diameter $0.32 \mathrm{~mm}$ and film thickness $0.50 \mu \mathrm{m}$ ). The employed temperature programme used was $\mathrm{T}_{\text {starting }}=40^{\circ} \mathrm{C}$ for $5^{\prime}$, rate $=10^{\circ} \mathrm{C} / \mathrm{min}$, $\mathrm{T}_{\text {final }}=150^{\circ} \mathrm{C}$ for $20^{\prime}$.

Electron paramagnetic resonance (EPR) spin trapping experiments were carried out with a Bruker ER 200 MRD spectrometer equipped with a TE 201 resonator, at a microwave frequency of $9.4 \mathrm{GHz}$. In a typical experiment, $\mathrm{TiO}_{2}-\mathrm{P} 25(20 \mathrm{mg})$ was suspended in the deaerated medium consisting of $\mathrm{CH}_{3} \mathrm{CN} / 2$-propanol $(4 / 1 \mathrm{v} / \mathrm{v})$ solution $(1 \mathrm{~mL})$ containing $\mathrm{LiClO}_{4}, \mathrm{NaClO}_{4}$ or $\mathrm{KPF}_{6}$ $\left(0.1 \mathrm{~mol} \mathrm{~L}^{-1}\right.$ when required), $\alpha$-phenyl $N$-tert-butyl nitrone (PBN, $\left.5 \times 10^{-2} \mathrm{~mol} \mathrm{~L}^{-1}\right)$ as spin trap and $\mathrm{O}_{2} \mathrm{NC}_{6} \mathrm{H}_{4} \mathrm{CHO}\left(1 \times 10^{-3} \mathrm{~mol} \mathrm{~L}^{-1}\right)$ as the electron acceptor. The samples were put into a flat quartz cell and irradiated directly in the EPR cavity $(\lambda>360 \mathrm{~nm})$. Deaeration has been carried out fluxing $\mathrm{N}_{2}$ and transferring the samples into the cell under a $\mathrm{N}_{2}$ saturated atmosphere. No signals were obtained in the dark and during irradiation of the solution in the absence of $\mathrm{TiO}_{2}$. 


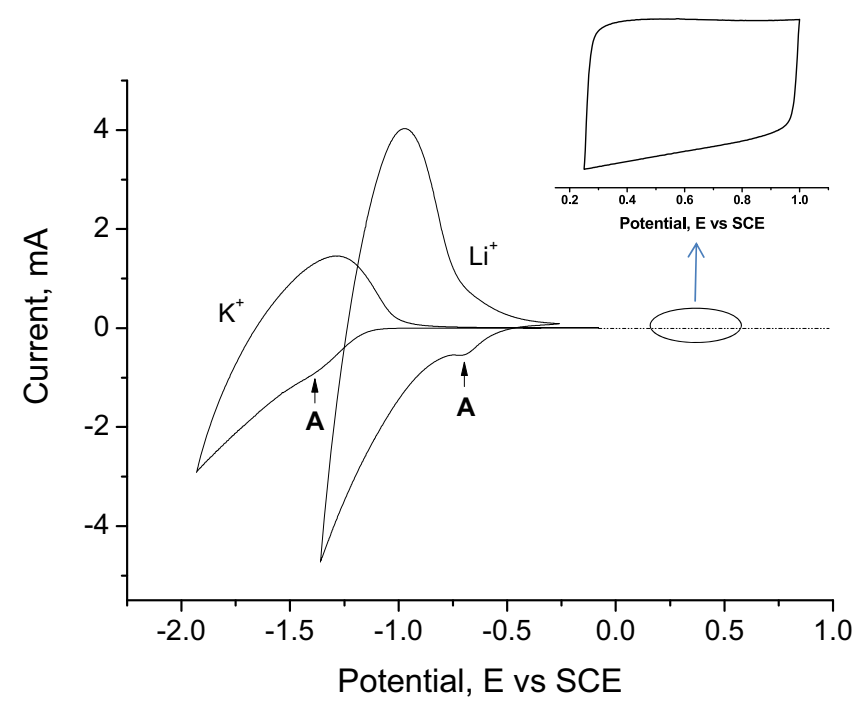

Fig. 1. Cyclic voltammetry curves in the dark for a $\mathrm{TiO}_{2}$ electrode in de-aerated solutions of $\mathrm{CH}_{3} \mathrm{CN} / 2$-propanol $(4: 1 \mathrm{v} / \mathrm{v})$ and $\mathrm{K}^{+}$or $\mathrm{Li}^{+}$as the electrolyte cation $\left(0.1 \mathrm{~mol} \mathrm{~L}^{-1}\right)$. Electrode geometric area: $1.1 \mathrm{~cm}^{2}$; scan rate: $50 \mathrm{mV} \mathrm{s}^{-1}$. The inset shows an expanded view of the voltammetry response for $\mathrm{TiO}_{2} / \mathrm{K}^{+}$at a scan rate of $100 \mathrm{mV} / \mathrm{s}$.

\section{Results and discussion}

\subsection{Electrochemical characterization}

Photocatalytic processes can be described using an electrochemical formalism [23] and electrochemical methods offer a precious and important tool for characterization of these systems [24]. We exploit the potentiality of these techniques of investigation in a continuation of our recent studies [6,7] on the effect of cations on surface energetics and its impact on photocatalytic reactions. In all cases, we found that the behaviour in electrolytes containing $\mathrm{Na}^{+}$is intermediate between those in electrolytes containing $\mathrm{Li}^{+}$and $\mathrm{K}^{+}$and we will accordingly focus on differences between these two cations. For example, in $\mathrm{NaClO}_{4}, \mathrm{E}_{\mathrm{fb}}$ from MottSchottky plots is $\sim-1,8 \mathrm{~V}$ vs SCE, which is an intermediate value between those determined in $\mathrm{LiClO}_{4}\left(-1.4 \mathrm{~V}\right.$ vs SCE) and $\mathrm{KClO}_{4}$ $(-2.0 \mathrm{~V}$ vs SCE$)$. The latter value is the same as found in a $\mathrm{TEAClO}_{4}$ (TEA = tetra-ethyl ammonium) electrolyte [6].

\subsubsection{Electrochemistry in the dark}

We devote some attention to the behaviour of 2-propanol that is chemisorbed at the surface and works as the hole scavenger in our photocatalytic experiments. It captures photo-generates holes efficiently, so enhancing the lifetime of electrons. 2-Propanol photo-oxidation also yields protons that are essential for the reduction of $\mathrm{O}_{2} \mathrm{NC}_{6} \mathrm{H}_{4} \mathrm{CHO}$, which turned out to be an excellent probe to examine the reactivity of the photo-generated electrons [6,7].

In general, any solution species interacting with the oxide surface could affect surface processes. In particular, the effect of electrolyte cations on the shape of cyclic voltammetry (CV) curves (Fig. 1) depends mainly on their adsorption on the surface in the absence of ion insertion inside the oxide [7]. In the adsorbed state, interactions are mainly interfacial phenomena involving electrostatic attraction of ions to the oxide surface; the smaller $\mathrm{Li}^{+}$, like protons, can interact more closely with the oxide surface than $\mathrm{K}^{+}$ and $\mathrm{Na}^{+}$and in consequence currents are seen to change more sharply in the presence of $\mathrm{Li}^{+}$.

The small peak identified as A in Fig. 1 is due to the filling of states attributed to defects located at grain boundaries $[25,26]$; oxygen vacancies, in particular, seemingly tend to concentrate at grain
Table 1

Effect of cations and 2-propanol addition on measured capacities.

\begin{tabular}{|c|c|c|}
\hline Cation & Capacitance $^{\mathrm{a}}(\mu \mathrm{F})($ no alcohol) & Capacitance $^{\mathrm{a}}(\mu \mathrm{F})$ (alcohol) \\
\hline $\mathrm{Li}^{+}$ & 6.30 & 12.5 \\
\hline $\mathrm{Na}^{+}$ & 3.85 & 15.2 \\
\hline $\mathrm{K}^{+}$ & 3.38 & 23.0 \\
\hline
\end{tabular}

a Calculated from cyclic voltammetry curves (inset of Fig. 1), see Material and methods section.

boundaries [27,28]. Monitoring the behaviour of this peak (Fig. 1) is often very informative since the intensity and position of the peak relative to $\mathrm{E}_{\mathrm{fb}}$ depends, among other, on the surface charge.

The voltammetric charge $\mathrm{Q}_{\mathrm{A}}$ (peak A, Fig. 1) recorded during the negative potential sweep corresponds to electron trapping by surface states below the conduction band. We observed earlier [7] that the interaction between 2-propanol and the $\mathrm{TiO}_{2}$ surface causes a significant perturbation of the surface charge associated with these surface defects. It is possible to envisage that the effect on peak A (Fig. 1) is due to dissociative adsorption on vacancies with formation of alkoxy intermediates. Indeed alcohols can be adsorbed both molecularly or dissociatively yielding alkoxy ( $\mathrm{R}-\mathrm{O})^{-}{ }_{\text {ads }}$ species (reaction (3)), and both computational and experimental evidence (from scanning tunnelling microscopy studies) for the cleavage of the alcohol O-H bond conclusively show that dissociative adsorption on incompletely coordinated surface Ti cations is more favourable than the molecular adsorption mode [18,29-31]:

$$
\left(\mathrm{CH}_{3}\right)_{2} \mathrm{CHOH} \rightarrow\left(\mathrm{CH}_{3}\right)_{2} \mathrm{CHO}^{-} \text {ads }+\mathrm{H}^{+}
$$

Dissociative adsorption eventually leads to vacancies filling and to $\mathrm{H}^{+}$adsorption on nearby bridge oxygens. As further discussed in the next section, formation of adsorbed alkoxy species is an important key to understanding the mechanism of photocatalytic reactions where alcohols are the holes scavengers.

It is not a secondary fact that charge transfer reactions often proceed via surface states as indeed is the case of the probe nitroaromatic aldehyde we monitor herein [6,7]. Since useful information is often obtained by testing the behaviour of surface states, we examined the effect of $\mathrm{K}^{+}$and $\mathrm{Li}^{+}$on the electrochemical response of the reduction process resulting in peak $\mathrm{A}$ (Fig. 1). Some difference between results in the presence of $\mathrm{Li}^{+}$and $\mathrm{K}^{+}$is appreciated but in all the influence of the cation nature on the charging of these deep states is seemingly marginal, probably because the amount of adsorbed cations is enough to avoid changes in the interfacial double layer. Details on the electrochemical results are given as Supplementary information.

In the more positive range of applied potentials (Fig. 1, insert), in the dark, the film is under depletion conditions and the total capacitance $C_{T}$ is given by [32]:

$C_{T}=\frac{\varepsilon_{o} \varepsilon_{r A}}{d}$

where $A$ is the surface area, $\varepsilon_{\mathrm{O}}$ is the permittivity of vacuum, $\varepsilon_{\mathrm{r}}$ is the relative permittivity of $\mathrm{TiO}_{2}$ and $\mathrm{d}$ is the film thickness. Experimental data show that capacities are constant as a function of potential $(-0.1$ to $0.8 \mathrm{~V})$ and average values, with added cations and in the absence and in the presence of 2-propanol, are reported in Table 1. It can be seen that addition of 2-propanol causes a meaningful increase of $\mathrm{C}_{\mathrm{T}}$ in the order $\mathrm{Li}^{+}<\mathrm{Na}^{+}<\mathrm{K}^{+}$. There is obviously no induced insertion of cations in these experiments, and changes (increase) in the dielectric constant of $\mathrm{TiO}_{2}\left(\varepsilon_{\mathrm{r}}\right)$ can be discounted, as are changes in the film thickness $d$. The total capacitance $C_{T}$ is actually given by [33].

$\left(C_{T}\right)^{-1}=\left(C_{\mathrm{sc}}+C_{\mathrm{sS}}\right)^{-1}+\left(C_{\mathrm{H}}\right)^{-1}$ 
where $C_{s c}$ is the space charge capacity, $C_{s s}$ is the surface states capacity and $C_{H}$ the double layer capacity. Since we operate in the presence of an excess electrolyte, $C_{H}$ is sufficiently large to be neglected in Eq. (5) and then $\mathrm{C}_{\mathrm{T}} \cong \mathrm{C}_{\mathrm{sc}}+\mathrm{C}_{\mathrm{ss}}$.

We speculate that the results of Table 1 may be explained by a localized charging of surface states by the adsorbed alcohol [34]. In support of this view, we remark the contrasting effect of cations. The case of $\mathrm{Li}^{+}$is interesting since the modest increase of the capacity upon 2-propanol addition may appear counter intuitive. We cannot provide a conclusive explanation but we advance the possibility that the effect of the cations resides in their interaction strength with the alcohol. So, the calculated binding energies of alkali metal cations $\left(\mathrm{Li}^{+}, \mathrm{Na}^{+}, \mathrm{K}^{+}\right)$to short chain alcohols show that affinities follow the order $\mathrm{Li}^{+}>\mathrm{Na}^{+}>\mathrm{K}^{+}[35]$. The formation of a positively charged complex between 2-propanol and the cations, in the solution phase, could hinder (although not suppress) the alcohol interaction with the surface that bears a positive charge due to adsorbed cations. Additionally, $\mathrm{Li}^{+}$is more strongly adsorbed than $\mathrm{Na}^{+}$and $\mathrm{K}^{+}$, in particular; it could seriously interfere with the dissociation of adsorbed alcohol molecules (reaction (1)) because protons directly released on the surface would have to compete with $\mathrm{Li}^{+}$for the same surface sites.

\subsubsection{Electrochemistry under illumination}

Illumination causes formation of electrons and holes; in our photocatalytic system, the latter are scavenged by 2-propanol, according to reaction (6):

$\left(\mathrm{CH}_{3}\right)_{2} \mathrm{CHOH}+2 \mathrm{~h}^{+} \rightarrow\left(\mathrm{CH}_{3}\right)_{2} \mathrm{CO}+2 \mathrm{H}^{+}$

both electrons and protons are captured in the reduction of $\mathrm{O}_{2} \mathrm{NC}_{6} \mathrm{H}_{4} \mathrm{CHO}$ to $\mathrm{H}_{2} \mathrm{NC}_{6} \mathrm{H}_{4} \mathrm{CHO}$ and, ultimately, to $\mathrm{H}_{2} \mathrm{NC}_{6} \mathrm{H}_{4} \mathrm{CH}_{2} \mathrm{OH}$. In the absence of the electron acceptor, electrons are photoaccumulated and charge can be screened by electrolyte cations [36].

In this case, the photo-accumulated charge $\mathrm{Q}$ can be extracted electrochemically, in the dark, by integrating the current as a function of time from different potentials $E_{i}$ to a final positive potential $E_{f}[7,37]$. This procedure gives important information on surface states [7] as well as on possible changes in the surface properties due to cation insertion.

In a typical experiment, the charge extracted following $10 \mathrm{~min}$ pre-illumination of an electrode in $\mathrm{K}^{+} / \mathrm{CH}_{3} \mathrm{CN}$ was 4 -fold higher than in $\mathrm{Li}^{+} / \mathrm{CH}_{3} \mathrm{CN}$. The charge extraction phenomenon is complicated by a number of processes taking place during illumination. Thus, on the one hand, the photo-oxidation of the adsorbed alcohol (reaction (3)) with formation of alkoxy radicals as a step in the overall reaction (6) occurs; their desorption will cause significant changes in the interface structure [7] as further discussed in Section 3.2 , possibly including re-creation of vacancies previously filled with 2-propanol in the dark.

On the other hand, subsequent re-equilibration in the dark can be slow and dependent on the phenomena taking place during illumination such as photo-insertion of cations into the oxide. From a macroscopic point of view, the relevant point in the present study is that the change of surface properties (formation of a different $\mathrm{Li}_{\mathrm{X}} \mathrm{TiO}_{2}$ phase) caused by cation photo-insertion is well documented for the small $\mathrm{Li}^{+}$[7 and refs therein]. Electrochemical insertion of $\mathrm{Na}^{+}$in anatase has been investigated with a focus on application in batteries [38]; apparently, however, the phenomenon is not reported to occur in the case of the larger $\mathrm{K}^{+}$or $\mathrm{TEA}^{+}$. We will confirm in the following sections that insertion has major impact in the photocatalytic process.

Another valid argument is that not only $\mathrm{Li}^{+}$or $\mathrm{Na}^{+}$but also protons (reaction (6)) can be inserted during the photo-charging process and this process can factually take place [39]. Although the electrolyte contains no free $\mathrm{H}^{+}$, still insertion of those produced at
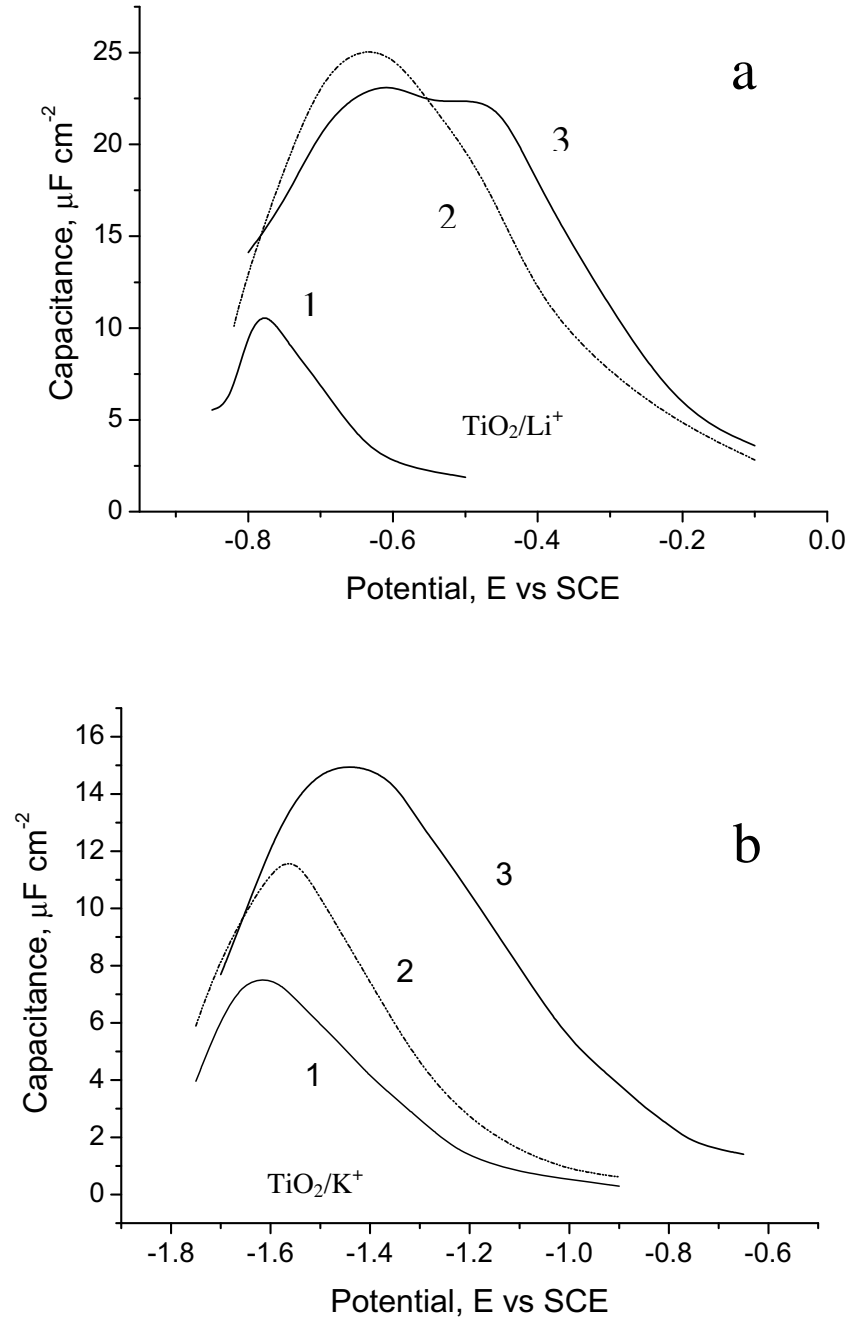

Fig. 2. Effect of electrolyte cations $\left(0.1 \mathrm{~mol} \mathrm{~L}^{-1}\right)$ on capacitance plots for $\mathrm{TiO}_{2}$ in $\mathrm{CH}_{3} \mathrm{CN}$ /2-propanol; data obtained from charge extracted in the dark re-oxidation process $(\mathrm{dQ} / \mathrm{dE})$ following pre-illumination (a) $\mathrm{TiO}_{2} / \mathrm{Li}^{+}$in the dark after preillumination for $0 \mathrm{~min}(1) ; 2 \mathrm{~min}(2)$ and $5 \mathrm{~min}(3)$; (b) $\mathrm{TiO}_{2} / \mathrm{K}^{+}$in the dark before illumination (1), after pre-illumination for $2 \mathrm{~min}(2)$ and $5 \mathrm{~min}(3)$.

the surface could occur simultaneously with, or instead of, $\mathrm{Li}^{+}$and $\mathrm{Na}^{+}$. In the case that $\mathrm{K}^{+}$or TEA $A^{+}$are the electrolyte cations, the sole insertion process might well be that of $\mathrm{H}^{+}$

$\mathrm{TiO}_{2}+\mathrm{H}^{+}+\mathrm{e}^{-} \rightarrow \mathrm{TiOOH}$

Capacitance plots from charge extracted in the dark re-oxidation process $(\mathrm{dQ} / \mathrm{dE})$, following pre-illumination, are shown in Fig. 2a and $\mathrm{b}$ for the case of electrolytes containing $\mathrm{Li}^{+}$and $\mathrm{K}^{+}$, respectively (cf. Fig. 1). On open circuit pre-illumination of the $\mathrm{TiO}_{2} / \mathrm{Li}^{+}$system (Fig. 2a), a broad peak at $-0.64 \mathrm{~V}$ is seen at first (curve 2 ) and, upon increasing exposure to light, the intensity of this peak decreases and a new peak appears at $-0.48 \mathrm{~V}$ (curve 3 ). These results are clearly different from those observed with $\mathrm{TiO}_{2} / \mathrm{K}^{+}$(Fig. 2b) where only a broad peak is seen (curve 1 ), shifting to more positive potentials as light treatment is prolonged (curve 2). Earlier we showed that $\mathrm{TiO}_{2} / \mathrm{TEA}^{+}$presents a similar behaviour [6] and since for both $\mathrm{K}^{+}$ and $\mathrm{TEA}^{+}$one can safely exclude significant photo-insertion, there is reason to assume that only the photo-generated $\mathrm{H}^{+}$can be inserted in the case that no protons are consumed in a reduction process.

By comparison, the more complex case of $\mathrm{TiO}_{2} / \mathrm{Li}^{+}$seems to suggest a co-insertion of $\mathrm{Li}^{+}$and $\mathrm{H}^{+}$

$\mathrm{xLi}^{+}+\mathrm{H}^{+}+2 \mathrm{TiO}_{2}+(1+\mathrm{x}) \mathrm{e}^{-} \rightarrow \mathrm{Li}_{\mathrm{x}} \mathrm{TiO}_{2}+\mathrm{TiOOH}$ 


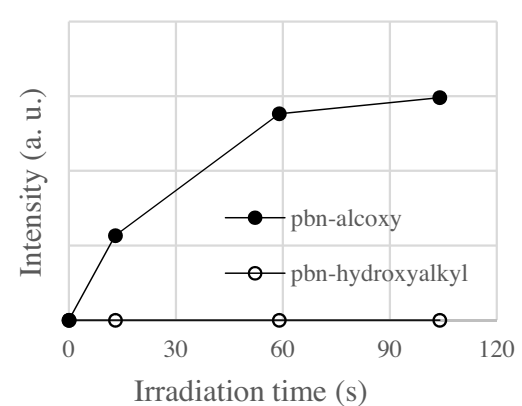

Fig. 3. Fixed-field EPR signal intensity of $\left[\mathrm{PBN}-\mathrm{OCH}\left(\mathrm{CH}_{3}\right)_{2}\right]$ ffull circles) and of [PBN-C $\left(\mathrm{CH}_{3}\right)_{2} \mathrm{OH}$ ] (empty circles) as a function of illumination time $(\lambda>360 \mathrm{~nm})$ of deaerated $\mathrm{TiO}_{2}$ suspensions in $\mathrm{CH}_{3} \mathrm{CN} / 2$-propanol (4/1) mixtures containing PBN $\left(5 \times 10^{-2} \mathrm{~mol} \mathrm{~L}^{-1}\right)$ and $\mathrm{KPF}_{6}$ or $\mathrm{LiClO}_{4}$ or $\mathrm{NaClO}_{4}(0.1 \mathrm{M}$ each $)$ indifferently.

in a degree that would be determined by the relative concentrations of the cations. In this context, we found that illumination at open circuit for 5 min produces $\sim 5 \mu \mathrm{mol} \mathrm{H}^{+}$on the basis of acetone analysis (reaction (6)), i.e., an amount about two orders of magnitude lower than that of $\mathrm{Li}^{+}$in the solution phase. Nonetheless, experiments do not negate co-insertion of protons since these are produced at the surface, whereas the adsorption of $\mathrm{Li}^{+}$requires the partial desolvation [40].

A deep knowledge of co-insertion is interesting, but to date it has been seemingly discussed in some detail only on a theoretical basis. DFT calculations indicate that both $\mathrm{H}^{+}$and $\mathrm{Li}^{+}$can insert into $\mathrm{TiO}_{2}$ and stabilize $\mathrm{Ti}^{3+}$ sites albeit in a different fashion. Inserted protons interact with $\mathrm{TiO}_{2}$ to form covalent $\mathrm{O}-\mathrm{H}$ bonds in contrast with the ionic character of the $\mathrm{O}-\mathrm{Li}^{+}$interaction [41]. There is probably a need of a separate in depth experimental scrutiny, which is beyond the scope of this paper. We limit ourselves to underlying that $\mathrm{H}^{+}$ (reaction (6)) should be the inserting species when the bulky $\mathrm{K}^{+}$ or $\mathrm{TEA}^{+}$are the electrolyte cations or when no electrolyte is used as further commented below. The salient point is that in the case of $\mathrm{Li}^{+}$insertion, there is a vast bulk of evidence of electrochemical or photochemical induced formation of a different phase $\left(\mathrm{Li}_{\mathrm{X}} \mathrm{TiO}_{2}\right)$ as we underlined earlier [7 and refs. therein], which has a major impact on the overall photocatalytic activity as discussed in the following.

\subsection{EPR spin trapping in 2-propanol photo-oxidation}

In the investigated photocatalytic system, 2-propanol (that is $20 \%$ in volume) works as a hole scavenger. It has been recently demonstrated that surface modifications due to photo-insertion and slow de-insertion of $\mathrm{Li}^{+}$ions dramatically change the adsorption of the alcohol on the $\mathrm{TiO}_{2}$ surface [7]. Pathways involving holes generally entail the formation of radical intermediates and, in this context, the EPR spin trapping technique is a powerful tool for detecting and distinguishing between the two possible radicals (iso-propoxy and hydroxy-isopropyl) originating from 2-propanol photo-oxidation [7,42-44]. For this reason, we decided to carry out EPR spin trapping experiments in the presence of the different alkali metal ions in order to gain insights into the effect possibly induced by cations on the photo-oxidation mechanism of the alcohol. Irradiation conditions employed in these experiments were the same used in the photocatalytic runs. In a typical experiment, as soon as light is switched on, a spectrum consisting of a triplet of doublets $\left(a_{N}=14.1 G, a_{H}=2.3 G\right)$ appears independently of the nature of the present electrolyte cation. By comparison with previous literature $[7,42]$ and considering the species present in the experiment, this adduct is attributed to the trapping of iso-propoxy radical by PBN. Fig. 3 (full circles) reports intensities of this paramagnetic adduct $\left[\mathrm{PBN}-\mathrm{OCH}\left(\mathrm{CH}_{3}\right)_{2}\right]^{\bullet}$ obtained at a fixed magnetic field as a function of illumination time.

Formation of this kind of radicals indicates that adsorption of 2-propanol in the dark is strong (reaction (3)) and generates alcoholate anions on the surface $[43,44]$, confirming electrochemical data presented above. As a consequence of illumination, reaction between the photo-generated holes and adsorbed alcoholate generates alkoxy radicals (reaction (9)) that can be trapped by PBN and detected.

$$
\left(\mathrm{CH}_{3}\right)_{2} \mathrm{CHO}^{-} \text {ads }+\mathrm{h}^{+}=\left(\mathrm{CH}_{3}\right)_{2} \mathrm{CHO}^{-}
$$

Samples after illumination were then kept in the dark for an interval of about ten minutes. During this time, equilibrium conditions very similar to the initial ones should be restored. Then, a second irradiation run was carried out. The obtained results (Fig. 4) clearly depend on the kind of cation present. In the case of $\mathrm{TiO}_{2} / \mathrm{K}^{+}$ (and of $\mathrm{TiO}_{2} / \mathrm{TEA}^{+}$, data not shown), the main paramagnetic adduct is still $\left[\mathrm{PBN}-\mathrm{OCH}\left(\mathrm{CH}_{3}\right)_{2}\right]^{\bullet}$, and its intensity increases with time as found during the first illumination period (full circles). In contrast, when $\mathrm{TiO}_{2} / \mathrm{Li}^{+}$is employed, a completely different behaviour is observed: a new triplet of doublets, broader than the previous one $\left(a_{N}=15.2 G, a_{H}=3.5 G\right)$, is recorded [7,42], ascribable to the adduct between PBN and hydroxyalkyl radicals of 2-propanol, [PBN-C $\left.\left(\mathrm{CH}_{3}\right)_{2} \mathrm{OH}\right]^{\bullet}$ (Fig. 4 empty circles). The formation of these radicals is an indication that alcohol adsorption decreases in consecutive illumination runs and holes react with surface $\mathrm{OH}$ groups giving $\mathrm{OH}^{\bullet}$ radicals that, in turn, extract a hydrogen atom from 2-propanol, forming $\left(\mathrm{CH}_{3}\right)_{2} \mathrm{C} \bullet \mathrm{OH}$ radicals (reaction (10)). These results point out that the first illumination in the presence of $\mathrm{Li}^{+}$ causes some important surface changes that inhibit adsorption of 2-propanol and favour its oxidation through a different mechanism. Interestingly, the observed behaviour of $\mathrm{TiO}_{2} / \mathrm{Na}^{+}$is intermediate between those observed with $\mathrm{TiO}_{2} / \mathrm{K}^{+}$and $\mathrm{TiO}_{2} / \mathrm{Li}^{+}$, likely indicating an effect of cations size on surface modification by photo-insertion.
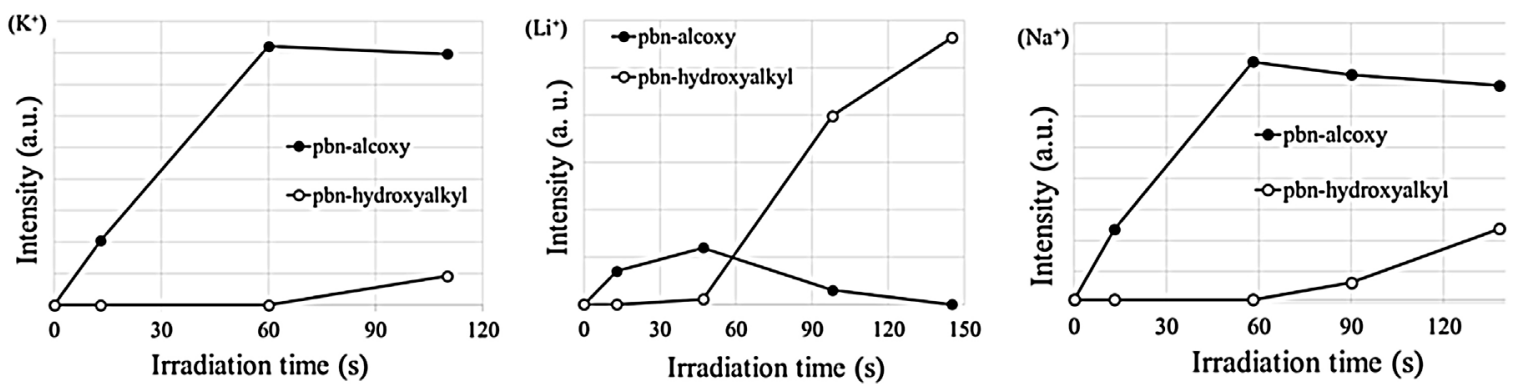

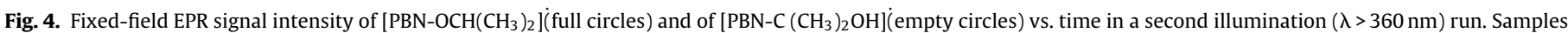

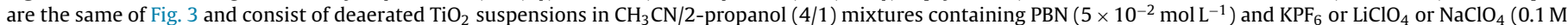

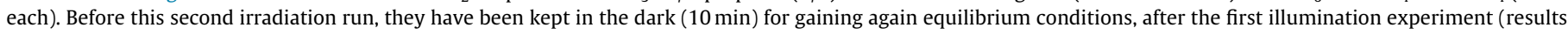
in Fig. 3). 


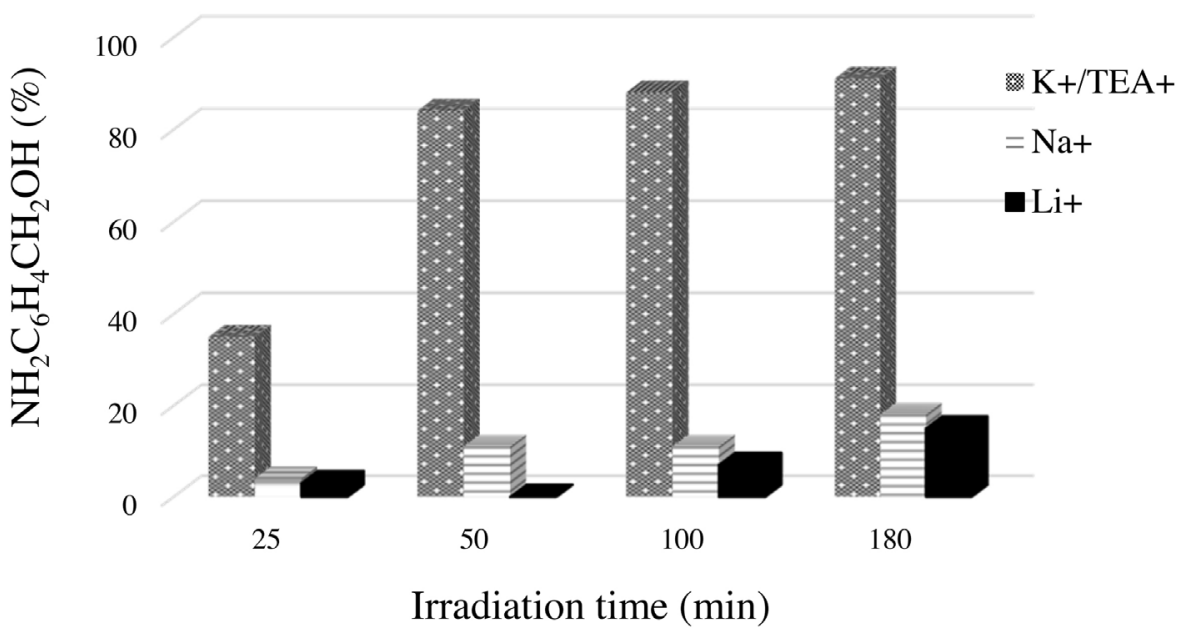

Fig. 5. $\mathrm{H}_{2} \mathrm{NC}_{6} \mathrm{H}_{4} \mathrm{CH}_{2} \mathrm{OH}$ yield (\%) vs. illumination time $(\lambda>360 \mathrm{~nm}) \mathrm{TiO}_{2}$ suspensions in $\mathrm{CH}_{3} \mathrm{CN} / 2$-propanol $(4 / 1)$ in the presence of $\mathrm{KPF}_{6}$ or $\mathrm{NaClO}_{4}$ or $\mathrm{LiClO}_{4}\left(0.1 \mathrm{~mol} \mathrm{~L}^{-1}\right)$.

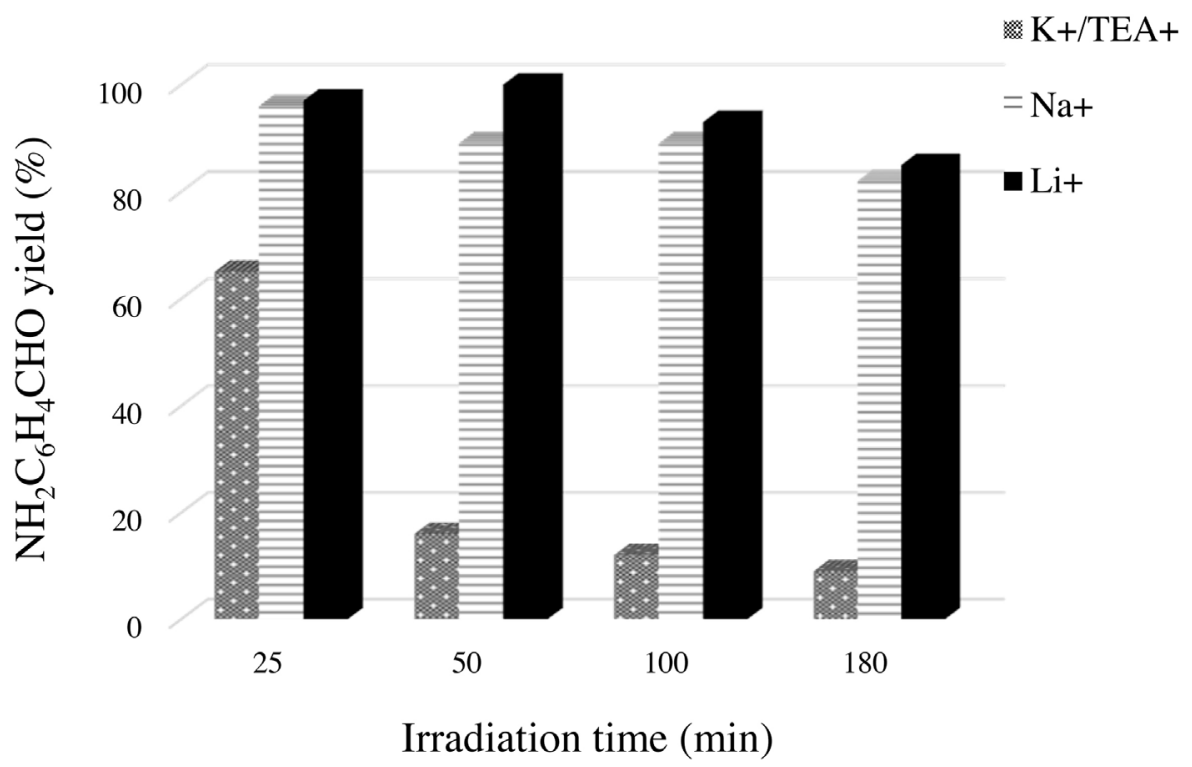

Fig. 6. $\mathrm{H}_{2} \mathrm{NC}_{6} \mathrm{H}_{4} \mathrm{CHO}$ yield (\%) vs. time irradiating $(\lambda>360 \mathrm{~nm}) \mathrm{TiO}_{2}$ suspensions in $\mathrm{CH}_{3} \mathrm{CN} / 2$-propanol (4/1) in the presence of $\mathrm{KPF}_{6}$ or $\mathrm{NaClO}_{4}$ or $\mathrm{LiClO}_{4}\left(0.1 \mathrm{~mol} \mathrm{~L}^{-1}\right)$.

$$
\mathrm{CH}_{3}-\underset{\mathrm{OH}}{\mathrm{CH}}-\mathrm{CH}_{3}+\mathrm{OH} \longrightarrow \mathrm{CH}_{3}-\underset{\mathrm{OH}}{\stackrel{\mathrm{C}}{\mathrm{C}}-\mathrm{CH}_{3}}+\mathrm{H}_{2} \mathrm{O}
$$

\subsection{Reduction photocatalysis}

In this section, focus is on the reduction of $\mathrm{O}_{2} \mathrm{NC}_{6} \mathrm{H}_{4} \mathrm{CHO}$ in illuminated $\mathrm{TiO}_{2}$ suspensions. The oxidation of 2-propanol by holes generates $\mathrm{H}^{+}$(reaction (6)) which, together with photogenerated electrons, are consumed in the partial (reaction (11)) and/or total reduction (reaction (12)) of the 4-nitrobenzaldehyde $\left(\mathrm{O}_{2} \mathrm{NC}_{6} \mathrm{H}_{4} \mathrm{CHO}\right)$ :

$$
\begin{aligned}
& \mathrm{O}_{2} \mathrm{NC}_{6} \mathrm{H}_{4} \mathrm{CHO}+6 \mathrm{H}^{+}+6 \mathrm{e}^{-} \rightarrow \mathrm{H}_{2} \mathrm{NC}_{6} \mathrm{H}_{4} \mathrm{CHO}+2 \mathrm{H}_{2} \mathrm{O} \\
& \mathrm{H}_{2} \mathrm{NC}_{6} \mathrm{H}_{4} \mathrm{CHO}+2 \mathrm{H}^{+}+2 \mathrm{e}^{-} \rightarrow \mathrm{H}_{2} \mathrm{NC}_{6} \mathrm{H}_{4} \mathrm{CH}_{2} \mathrm{OH}
\end{aligned}
$$

in $\mathrm{TiO}_{2} / \mathrm{K}^{+}$, reaction (11) is complete in $\sim 5 \mathrm{~min}$ and during this time the concentration of $\mathrm{H}_{2} \mathrm{NC}_{6} \mathrm{H}_{4} \mathrm{CH}_{2} \mathrm{OH}$ (reaction (12)) is negligible. We found that for longer illumination times, $\mathrm{H}_{2} \mathrm{NC}_{6} \mathrm{H}_{4} \mathrm{CHO}$ decreases at a rate of $4.7 \times 10^{-11} \mathrm{~mol} \mathrm{~s}^{-1}$ and $\mathrm{H}_{2} \mathrm{NC}_{6} \mathrm{H}_{4} \mathrm{CH}_{2} \mathrm{OH}$ forms at a rate of $3.7 \times 10^{-11} \mathrm{~mol} \mathrm{~s}^{-1}$. This is essentially what we observed earlier in $\mathrm{TiO}_{2} / \mathrm{TEA}^{+}[6]$, and the likely reason for this sim- ilarity is that for both $\mathrm{K}^{+}$and $\mathrm{TEA}^{+}$the large ionic radius somehow limits their interaction with the surface in comparison with $\mathrm{Li}^{+}$.

We showed earlier [6] that photo-reduction of $-\mathrm{NO}_{2}$ group occurs via surface states, whereas reduction of the $-\mathrm{CHO}$ group in both $\mathrm{TiO}_{2} / \mathrm{K}^{+}$and $\mathrm{TiO}_{2} / \mathrm{TEA}^{+}$takes place only after that the $-\mathrm{NO}_{2}$ group is completed. Occurrence of reaction (12) requires a negative shift of the conduction band potential [14] brought about by accumulation of electrons occurring after trap filling [6], which also creates the conditions for cations insertion. Due to the larger ionic radius, $\mathrm{K}^{+}$and $\mathrm{TEA}^{+}$cannot be photochemically (or electrochemically) inserted inside $\mathrm{TiO}_{2}$ and electron accumulation is instead accompanied by $\mathrm{H}^{+}$insertion (reaction (6)) as we commented in Section 3.1.

The effects of electron accumulation in $\mathrm{TiO}_{2} / \mathrm{K}^{+}$and $\mathrm{TiO}_{2} / \mathrm{TEA}^{+}$ are not seen when the electrolyte cation is $\mathrm{Li}^{+}$. Comparison of the results of Figs. 5 and 6 confirms the pronounced influence of the nature of cations on products distribution, in agreement with the electrochemical data (Section 3.1.2); in particular, the presence of $\mathrm{Li}^{+}$leads to selective formation of $\mathrm{H}_{2} \mathrm{NC}_{6} \mathrm{H}_{4} \mathrm{CHO}$, strongly inhibiting full reduction to $\mathrm{H}_{2} \mathrm{NC}_{6} \mathrm{H}_{4} \mathrm{CH}_{2} \mathrm{OH}$ [7]. Moreover, the EPR spin trapping experiments (Section 3.2) demonstrate a dramatic alteration of the 2-propanol adsorption mechanism. From these results, we 
can state that illumination of $\mathrm{TiO}_{2} / \mathrm{Li}^{+}$system profoundly affects the surface properties [7]. We want to draw attention to this particular aspect and highlight an interesting literature work emphasizing that irreversible phase transitions, like those we observe with $\mathrm{Li}^{+}$, are not a feature of inserted protons [45].

As already underlined above, the photocatalytic activity of $\mathrm{TiO}_{2} / \mathrm{Na}^{+}$is intermediate between that of $\mathrm{TiO}_{2} / \mathrm{K}^{+}$and $\mathrm{TiO}_{2} / \mathrm{Li}^{+}$. However, under prolonged irradiation times, the behaviour of $\mathrm{TiO}_{2} / \mathrm{Na}^{+}$is more similar to that of $\mathrm{TiO}_{2} / \mathrm{Li}^{+}$than that of $\mathrm{TiO}_{2} / \mathrm{K}^{+}$ (Figs. 5 and 6). Indeed, $\mathrm{H}_{2} \mathrm{NC}_{6} \mathrm{H}_{4} \mathrm{CHO}$ is the main product also in the presence of $\mathrm{Na}^{+}$, even after prolonged (ex. $180 \mathrm{~min}$ ) irradiation (Fig. 6). Interestingly, $\mathrm{Na}^{+}$insertion is also possible and documented [46].

\section{Conclusions}

This work is a continuation of the previous investigations and aims to get a picture as complete as possible on the influence of the nature of the electrolyte cations on surface energetics. We underline the importance of photocatalysis in a regime of electrons photo-accumulation as an approach to understanding and optimizing the semiconductor surface energetics. The multistep photo-reduction of 4-nitrobenzaldehyde $\left(\mathrm{O}_{2} \mathrm{NC}_{6} \mathrm{H}_{4} \mathrm{CHO}\right)$ on $\mathrm{TiO}_{2}$ is a model reaction particularly suitable for examining the factors governing the photocatalytic selective reduction.

In conditions where illumination leads to the build-up of electrons in $\mathrm{TiO}_{2}$, the excess charge is compensated by adsorption and/or lattice insertion of small electrolyte cations such as $\mathrm{Li}^{+}$ and (to a lesser degree) $\mathrm{Na}^{+}$. This phenomenon has been frequently discussed in connection with dye sensitized solar cells and electrochromic devices but has been usually disregarded in photocatalytic applications.

Using electrochemical methods, EPR spin trapping spectroscopy and analysis of product, we prove the important role of 2-propanol, which is the hole scavenger. Adding that the photo-oxidation of 2-propanol yields protons necessary for the reduction of $\mathrm{O}_{2} \mathrm{NC}_{6} \mathrm{H}_{4} \mathrm{CHO}$. It is concluded that cations cause surface changes in the order $\mathrm{TEA}^{+}=\mathrm{K}^{+}<\mathrm{Na}^{+}<\mathrm{Li}^{+}$that affect adsorption processes of charge scavengers as well as band edge shifts.

\section{Appendix A. Supplementary data}

Supplementary data associated with this article can be found, in the online version, at http://dx.doi.org/10.1016/j.cattod.2016.09. 008.

\section{References}

[1] G. Palmisano, E. Garcia-Lopez, G. Marcì, V. Loddo, S. Yurdakal, V. Augugliaro, L. Palmisano, Chem. Commun. 46 (2010) 7074-7089.

[2] N. Hoffmann, Aust. J. Chem. 68 (2015) 1621-1639.

[3] W. Song, M.K. Brennaman, J.J. Concepcion, J.W. Jurss, P.G. Hoertz, H. Luo, C. Chen, K. Hanson, T.J. Meyer, J. Phys. Chem. C 115 (2011) 7081-7709.
[4] P. Lianos, J. Hazard. Mater. 185 (2011) 575-590.

[5] J. Schneider, M. Matsuoka, M. Takeuchi, J. Zhang, Y. Horiuchi, M. Anpo, D.W. Bahnemann, Chem. Rev. 114 (2014) 9919-9986.

[6] A. Molinari, A. Maldotti, R. Amadelli, Chem. Eur. J. 20 (2014) 7759-7765.

[7] A. Molinari, A. Maldotti, R. Amadelli, J. Electroanal. Chem. 755 (2015) 143-150.

[8] J. Idígoras, T. Berger, J.A. Anta, J. Phys. Chem. C 117 (2013) 1561-1570 (and refs, therein).

[9] T. Torimoto, R.J. Fox III, M.A. Fox, J. Electrochem. Soc. 143 (1996) 3712-3717.

[10] J.G. Highfield, M. Gratzel, J. Phys. Chem. 92 (1988) 464-467.

[11] A. Listorti, C. Creager, P. Sommeling, J. Kroon, E. Palomares, A. Fornelli, B. Breen, P.R.F. Barnes, J.R. Durrant, C. Law, B. O’Regan, Energy Environ. Sci. 4 (2011) 3494-3501.

[12] Y. Kohtani, E. Kamoi, H. Yoshoka, Miyabe, Catal. Sci. Technol. 4 (2014) 1084-1091 (and refs. therein).

[13] F. Cao, G. Oskam, P. Searson, J.M. Stipkala, T.A. Heimer, F. Farzad, G. Meyer, J. Phys. Chem. B 99 (1995) 11974-11980.

[14] D. Mandal, T.W. Hamann, ACS Appl. Mater. Interfaces 8 (2016) 419-424.

[15] D.F. Watson, G.J. Meyer, Coord. Chem. Rev. 248 (2004) 1391-1406.

[16] K. Fredin, J. Nissfolk, G. Boschloo, A. Hagfeldt, J. Electroanal. Chem. 609 (2007) 55-60

[17] Z. Bi, M.P. Paranthaman, P.A. Menchhofer, R.R. Dehoff, C.A. Bridges, M. Chi, B. Guo, X.G. Sun, S. Dai, J. Power Sources 222 (2013) 461-466.

[18] Z. Dohnálek, I. Lyubinetsky, R. Rousseau, Prog. Surf. Sci. 85 (2010) 161-205.

[19] M.J. Jackman, K.L. Syres, D.J.H. Cant, S.J.O. Hardman, A.G. Thomas, Langmuir 30 (2014) 8761-8769.

[20] T. Fröschl, U. Hörmann, P. Kubiak, G. Kučerová, M. Pfanzelt, C.K. Weiss, R.J. Behm, N. Hüsing, U. Kaiser, K. Landfester, M. Wohlfahrt-Mehrens, Chem. Soc. Rev. 41 (2012) 5313-5360.

[21] U. Kang, H. Park, Appl. Catal. B: Environ. 140-141 (2013) 233-240.

[22] B. Erdem, R.A. Hunsicker, G.W. Simmons, E.D. Sudol, V.L. Dimonie, M.S. El-Aasser, Langmuir 17 (2001) 2664-2669.

[23] M. Neumann-Spallart, Chimia 61 (2007) 806-809.

[24] M. Jankulovska, T. Berger, T. Lana-Villareal, R. Gómez, Electrochim. Acta 62 (2012) 172-180

[25] T. Berger, T. Lana-Villareal, D. Monllor-Satoca, R. Gómez, Electrochem. Commun. 8 (2006) 1713-1718.

[26] T. Berger, J.A. Anta, Anal. Chem. 84 (2012) 3053-3057.

[27] K. McKenna, A. Shluger, Appl. Phys. Lett. 95 (2009) (222111-222111-3).

[28] T. Oyama, N. Wada, H. Takagi, Phys. Rev. B 82 (2010) (134107-134107-10).

[29] J.N. Muir, Y. Choi, H. Idriss, Phys. Chem. Chem. Phys. 14 (2012) 11910-11919.

[30] Y.K. Kim, C.-C. Hwang, Surf. Sci. 605 (2011) 2082-2086.

[31] I.A. Shkrob, M.C. Sauer Jr., D. Gozstola, J. Phys. Chem. B 108 (2004) $12512-12517$.

[32] R. van de Krol, A. Goossens, J. Schoonman, J. Phys. Chem. B 103 (1999) $7151-7159$.

[33] S.R. Morrison, Electrochemistry at Semiconductors and Oxidized Metal Electrodes, Plenum Press, New York, 1980, p. 123

[34] W. Lorenz, C. Engler, Surf. Sci. 95 (1980) 431-446

[35] N.L. Ma, F.M. Siu, C.W. Tsang, Chem. Phys.Lett. 322 (2000) 65-72.

[36] A. Wahl, J. Augustynski, J. Phys. Chem. B 102 (1998) 7820-7828.

[37] N.W. Duffy, L.M. Peter, R.M.G. Rajapakse, K.G.U. Wijayantha, Electrochem. Commun. 2 (2000) 658-662.

[38] L. Wu, D. Bresser, D. Buchholz, G.A. Giffin, C. Ramirez Castro, A. Ochel, S. Passerini, Adv. Energy Mater. 5 (2015) 1401142, 11 pp.

[39] B.I. Lemon, J.T. Hupp, J. Phys. Chem. 100 (1996) 14578-14580.

[40] N.F. Carvalho, J.R. Pliego Jr., Phys. Chem. Chem. Phys. 17 (2015) 26745-26755.

[41] J. Zhang, M. Steigerwald, L. Brus, R.A. Friesner, Nano Lett. 14 (2014) 1786-1789.

[42] G.R. Buettner, Free Rad. Biol. 3 (1987) 259-303.

[43] A. Molinari, M. Montoncello, H. Rezala, A. Maldotti, Photochem. Photobiol. Sci. 8 (2009) 613-619.

[44] A. Molinari, A. Maldotti, R. Amadelli, Curr. Org. Chem. 17 (2013) 2382-2405.

[45] D. Dini, F. Decker, J. Appl. Electrochem. 26 (1996) 647-653.

[46] L. Wu, D. Bresser, D. Buchholz, G.A. Giffin, C. Ramirez Castro, A. Ochel, S Passerini, Adv. Energy Mater. 5 (2015) 1401142, 11 pp. 